\title{
A Study of Appraisal in Chinese Academic Book Reviews
}

\author{
Dongmei Wang \\ Department of Foreign Languages, Dalian University of Technology, 116024, Dalian, China \\ Xuehua An \\ Department of Foreign Languages, Dalian University of Technology, 116024, Dalian, China
}

\begin{abstract}
This article employed Appraisal theory to study the rhetoric and stylistic features of Chinese academic book reviews. A corpus of 30 Chinese academic book reviews were studied from the perspective of the "attitude resources" employed by the book reviewers to present his/her opinion on the book under review, and the perspective of the "engagement resources" by which the reviewers position their authorial voices with respect to, and engage with, the other voices and alternative positions.
\end{abstract}

Index Terms - appraisal theory, academic book reviews, discourse analysis

\section{INTRODUCTION}

The academic book review is an important sub-genre of academic discourse. The major purpose of this special genre, usually published in international journals, is to introduce a new book to the general readers in an academic discipline, and at the same time, to "evaluate the scholarly work of a professional peer within the scholarly community" (Lindholm-Romantschuk, 1998, p. 40). From the perspective of Systemic Functional Linguistics, the three variables of the context of situation through which the genre of academic book reviews is realized can be briefly described as follows: (1) field: information about the content of the book as well as the reviewer's opinion of the book will be provided; (2) tenor: the reviewer provides information and the readers receive the information, and the reviewer tries to persuade the readers to accept his opinion of the book; (3) mode: formal written language published in academic journals. We should say that the deepest study on academic book reviews was done by Hyland (2004) in his work Disciplinary Discourses: Social Interactions in Academic Writing. In his research Hyland studied hundreds of academic book reviews from more than twenty disciplines, all of which were publish in 1997. Through observing how book reviewers 'praise' and 'criticize' the book under review, Hyland concluded that the reason why soft discipline and hard discipline practice 'praise' and 'criticism' differently is because different disciplinary cultures' requirements are different. At the level of ethnic culture, Salager-Meyer and Alcaraz Ariza (2004) compared criticisms in medical book reviews, and found that French, English, and Spanish book reviewers used criticism differently in terms of frequency, indirectness and the way of mitigating criticisms. For example, it is the Spanish book reviewer who was found to have made the most criticisms in their book reviews. And a lot of mitigation expressions were employed by Spanish and French reviewers to make their criticism mild and easy to be accepted. In contrast, English reviewers were found to make critical points more directly without using those mitigation expressions. Another contrastive study of book reviews written by people from different national cultures was conducted by Hiroko Itakura and Amy B.M. Tsui (2011). Their paper investigated how English and Japanese book reviews make critical points in their book reviews. They collected 20 English and 20 Japanese linguistics book reviews. Their findings show that Japanese book reviews have a lot of striking differences from the English book reviews. 'Rhetorical questions', 'self-denigration', 'recasting problems as potential for future research' and 'attributing problems to the next generation' are used only in Japanese reviews. In addition, Ana I. Moreno and Lorena Suarez (2008) conducted a research to compare English and Spanish book reviewers' ways to show their positive and negative attitude to the books under review. Their results suggest that compared with the English book reviewers, peninsular Spanish writers of literary academic book reviews are, generally speaking, much less critical and are less likely to evaluate the book under review negatively.

All the previous studies mentioned above suggest that academic book review is a culture-specific sub-genre of academic discourse, both in terms of disciplinary culture and in terms of ethnic culture. The present study applies the concept of "appraisal" and "generic structure" to the analysis, with an aim of investigating how academic book reviewers in Chinese cultural context employ appraisal resources in each generic stage to produce a coherent, reader-friendly prose, and at the same time engage his or her readers (book author and other general readers).

\section{APPRAISAL THEORY}

Appraisal Theory concerns about the interpersonal meaning of a language. It is considered to be a significant development of the theory within the paradigm of Systemic Functional Linguistics. The major concerns of Appraisal 
Theory include how writers or speakers express their stance toward the things or ongoing events in the world, how they express their agreement or disagreement with the potential responses form the other readers, and how they establish and strengthen their identities in a text or discourse. Martin and White (2005, p. 20) believe that appraisal items in a language should be assigned to the rank of discourse semantics. The level of discourse semantics is more abstract than the level of grammar and lexis, which is more abstract than the level of phonology and graphology. The highest rank, discourse semantics, is about how to organize clauses into a meaningful discourse. The function practiced by appraisal items in a discourse is to help writers or speakers to express their evaluation, negotiate their relationship with the respondents, and establish their persona.

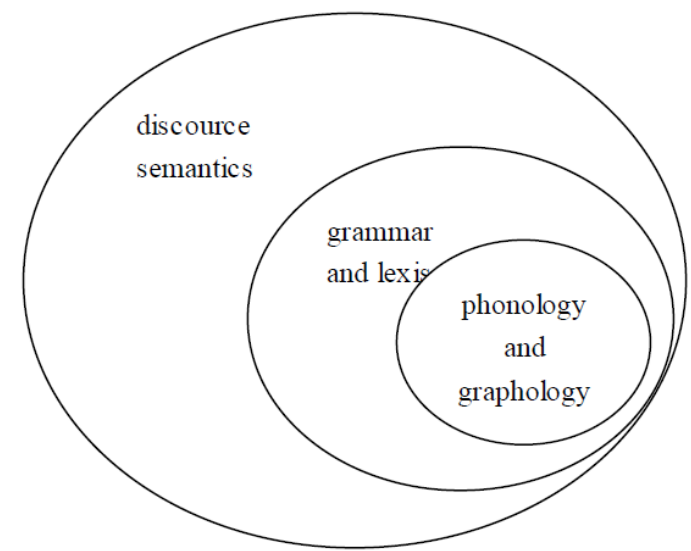

Figure I. Language strata (Martin \& White, 2005)

According to Martin \& White (2005), appraisal items can be employed to express people's attitudes, positive or negative feelings towards material things or social events. In this sense, attitude is classified into their minor system: affect, judgment and appreciation. Modality is another aspect which has attracted linguists' attention. Within the paradigm of Appraisal Theory, modality helps writers or speakers to show whether they are certain, confident or committed about certain issues. The term 'engagement' is used in Appraisal Theory to substitute the term 'modality'.

\section{A. Attitude}

A subsystem within Attitude is called 'affect'. The linguistic terms in this category are those that express human beings' emotive reaction. In the following examples about human beings' emotion, we can find dis/inclination, un/happiness, in/security, and dis/satisfaction. According to Martin \& White (2005), affect items are a natural part of our languages because we human beings are born with the need to express our feelings towards the world.

TABLE I.

LEXICAL REALIZATION OF AFFECT (MARTIN \& WHITE, 2005)

\begin{tabular}{|l|l|l|}
\hline Affect & Positive & Negative \\
\hline dis/inclination & demand, request & afraid \\
\hline un/happiness & buoyant, adore & gloomy, broken-hearted \\
\hline in/security & trusting, together & startled, freak out \\
\hline dis/satisfaction & absorbed, satisfied & sick of, fed up with \\
\hline
\end{tabular}

Another subsystem within Attitude is called 'judgment'. Judgment refers to human beings' attitude towards behavior. Judgment items include expressions about whether a person's behavior is normal, whether he is capable, whether he is reliable, whether he is trustworthy, or whether he is moral, etc. Positive judgment is for the good behaviors that we admire, while negative judgment is for the bad behavior that we criticize.

TABLE II.

LEXICAL REALIZATION OF JUDGMENT (MARTIN \& WHITE, 2005)

\begin{tabular}{|l|l|l|}
\hline Judgment & Positive & Negative \\
\hline normality & predictable, cool, fashionable & unpredictable, erratic, out-of-date \\
\hline capacity & witty, humorous, expert, successful & dull, dreary, inexpert, unsuccessful \\
\hline tenacity & cautious, careful, loyal, constant & rash hasty, disloyal, inconstant \\
\hline veracity & frank, discrete, tactful & deceptive, blunt, blabbermouth \\
\hline propriety & modest, humble, respectful, generous & snobby, arrogant, discourteous \\
\hline
\end{tabular}

Appreciation is a kind of evaluation, not on human beings' behaviors, but on things, whether natural or artificial. Reaction is about whether the object attracts us or not. Composition is about whether the object is in order. And valuation is about whether the object is worthwhile. 
TABLE III.

LEXICAL REALIZATION OF APPRECIATION (MARTIN \& WHITE, 2005)

\begin{tabular}{|l|l|l|}
\hline Appreciation & Positive & Negative \\
\hline Reaction 1 & moving, lively, dramatic & dry, flat, tedious \\
\hline reaction 2 & good, appealing, enchanting & yuk, ugly, revolting \\
\hline composition 1 & logical, shapely, unified & flawed, disorganized, shapeless \\
\hline composition 2 & elegant, rich, detailed & simplistic, wooly, monolithic \\
\hline valuation & profound, creative, genuine & fake, useless, bogus \\
\hline
\end{tabular}

\section{B. Engagement}

Engagement refers to the linguistic items that help the writer or the speaker to engage in a dialogue with the value positions the discourse is talking about or with the people who are addressed. Linguist Voloshinov expressed the nature of human beings' interaction like this:

The actual reality of language-speech is not the abstract system of linguistic forms, nor the isolated monologic utterance, and not the psychological act of its implementation, but the social event of verbal interaction implemented in an utterance or utterances (Voloshinov, 1995, p.138)

In Appraisal Theory, engagement system is composed of monogloss and hetergloss. Within the category of monogloss, bare assertion is expressed as the only one voice to be heard, which is considered to be intersubjectively neutral, and leaves no open space for alternative voices. Within the category of heterogloss, two sub-categories are included. They are dislogistically contractive items like 'disclaim' and 'proclaim', and dialogistically expansive items like 'entertain' and 'attribute'. The following table shows the monoglossic and heteroglossic features of our utterances:

TABLE IV.

MONOGLOSS AND HETEROGLOSS

\begin{tabular}{|l|l|}
\hline monoglossic & heterogloss \\
\hline This book is thought-provoking. & This book is not thought-provoking. \\
& Professor Mair said this book is thought-provoking. \\
& There can be no denying that this book is thought-provoking. \\
& In my view, this book is thought-provoking. \\
\hline
\end{tabular}

\section{Methodology}

The data of present study is composed of a corpus of 30 Chinese reviews, written by competent L 1 writers and experienced researchers in the field of linguistics. Four criteria were used to select the book reviews. First, we chose book reviews from the same academic discipline. The journals selected for the Chinese academic book reviews are: 外 语教学与研究，修辞学习， and中国语文. These journals were chosen because they are regarded as authoritative in the field of linguistics and only good reviews could be accepted and published. The second criteria is the historical time, because this factor may affect the type and frequency of appraisal used in the corpora (Salager-Meyer, 2006). So in the present study, only texts published form 2008 to 2011 were included. The third criteria is that only the book reviews written by a single reviewer were chosen, and that was to "eliminate stylistic differences between individual reviewers" (Hiroko Itakura \& Amy B.M. Tsui, 2011). The fourth criteria is the length of the book reviews. Since the length of individual texts is considered as a potential confounding factor (Ana I. Moreno \& Lorena Suarez, 2008), we excluded those academic book reviews that are too long or too short. Table 4 below shows the average number of words per book review and the average number of words of the corpus

TABLE V.

NUMBER OF WORDS IN THE CHINESE BOOK REVIEW CORPUS

\begin{tabular}{|l|l|}
\hline & Chinese academic book reviews(30) \\
\hline Total number of words & 32,610 \\
\hline Average number of words per book review & 1,087 \\
\hline
\end{tabular}

All the reviews in the two sub-corpora were analyzed at different generic structure stages. Martin (1984, p. 25) defines genre as a staged, goal-orientated, and purposeful social activity that people engage in as members of their culture. "Social because we participate in genres with other people; goal orientated because we use genres to get things done; staged because it usually takes us a few steps to reach our goals" (Martin \& White, 2005, p. 32-33). From the perspective of appraisal, the kinds of evaluations that a genre employ to attain its goals and how it displays these evaluations would attract the researchers (Martin \& White, 2005, p. 33). Based on Martin's theory of generic structure, the present study suggests that academic book review can be divided into three stages: INTRODUCTION, OVERVIEW, and EVALUATION. INTRODUCTION, as an optional stage, brings the book and its author into the picture and gives them a preliminary over-all evaluation. OVERVIEW, as an obligatory stage, outlines the book under review, provides an account of book's major elements. This part is usually interspersed with evaluation from the reviewer. EVALUATION is another obligatory stage where the reviewer comes to a final evaluation of the book as a whole and may appraise the author as successful or not in writing this book. 


\section{FINDINGS}

A prominent feature of the appraisal resources in academic book reviews is that they seem to permeate the whole text from the beginning to the end. Almost every stage of an academic book review is filled with various instances of evaluation. Table 5 illustrates the appraisal resources we found in the 3 generic stages of the 30 Chinese academic book reviews.

Generally speaking, the frequency of affect is much lower than that of judgment and appreciation in Chinese academic book review texts. The reviewer seldom expresses his opinion of the book under review by talking about his own emotional reactions, probably because affect is the most subjective among the three subcategories of attitude and it seems not professional and convincing enough to comment by relying too much on affective resources. Instead, evaluation of a book is mainly achieved through appreciation values targeted at the book or judgment values targeted at the book author. And we found more appreciation than judgment across the three genetic stages. That is probably because, compared with an evaluation on things, an evaluation on people is more likely to be challenged.

TABLE VI.

DISTRIBUTION OF CHINESE APPRAISAL RESOURCES ACROSS DIFFERENT GENERIC STAGES

\begin{tabular}{|l|l|l|l|}
\hline DISTRIBUTION OF CHINESE APPRAISAL RESOURCES ACROSS DIFFERENT GENERIC STAGES \\
\hline AFpraisal resources & Introduction (per thousand words) & Overview (per thou sand words) & Evaluation (per thousand words) \\
\hline JUDGEMENT & 6.1 & 3.3 & 10.2 \\
\hline APPRECIATION & 11.1 & 9.4 & 16.4 \\
\hline
\end{tabular}

\section{A. Appraisal at the Generic Stage of Introduction}

The analysis of the Chinese academic book reviews reveals that in the generic stage of Introduction, there are more resources used to express the reviewers' AFFECT than in the Overview stage; and the resources for AFFECT in the Evaluation outnumber the first two stages. In the opening of book reviews, 8 instances of positive AFFECT were found in the book review corpus. All of the 8 instances of AFFECT are used to show the reviewers inclination or satisfaction. In the following examples, the reviewer used one sentence from a poem to show how cheerful he/she was when he/she finally had the opportunity to read the reviewed book.

(1) “千呼万唤始出来”。

(Translation: Finally it showed up!)

(2) 数年前, 听到郑子瑜先生编写我国第一部规模宏大的修辞学通史, 我是士分高兴的。现在, 看到《中国修 辞学通史》的出版, 怎不令人万分喜悦呢!

(Translation: Several years ago, I was glad when I was told that Mr. Zheng was compiling a book about the history of Chinese rhetorics. Now, I was hilarious when I finally saw the book got published.)

In the first example, the reviewer didn't reveal his/her AFFECT directly, but the idiomatic meaning of the sentence helped expressed how much he/she longed for the publish of the reviewed book in a symbolic way. While in the second example, the review's love of the book was expressed directly and assertively.

Just like the resources of AFFECT, the resources of JUDGMENT in the Introduction stage outnumber that in the Overview stage, but are less than that in the Evaluation stage. All the judgments of the book author are positive, and the praises are directed to the book authors' talent, their capacity and their contribution the research in their fields of study.

For example:

(3) 本书作者是美国语言学界颇具影响力的青年语言学家之一。

(Translation: The author of the book is one of the most influential young linguists in America.)

(4) 郑先生是著名的语言学家, 他对古文有着丰赡的学养。

(Translation: Mr. Zheng is a well-known linguist, and he has quite a deep understanding on Chinese Classics.)

In the Chinese academic book reviews, we also found some instances of self-judgment: the judgment on the book reviews by themselves. All of these judgments can be labeled as self-denigration.

For example:

(5) 本人才疏学浅, 如有评论不当之处, 敬请谅解。

(Translation: The reviewer of the book is not knowledgeable, so if the review is not appropriate, please forgive me.)

The self-denigration in the Introduction stage is used here to reduce the face-threat of the book review. By judging oneself negatively as "not knowledgeable", the book reviewer used the negative politeness strategy to establish solidarity with the book author. Attending to the face needs of the book reviewer is one of the concerns of book reviewers since the unfolding review is sure to be full of critical comments on the book and its author.

\section{B. Appraisal at the Generic Stage of Overview}

In the stage of Overview, the reviewer is expected to take a neutral standing to present the outline of the reviewed book objectively to the readers. So the number of appraisal resources in this stage is fewer compared with the other two stages. In this stage, the book reviewers represent the book authors to introduce the reviewed books to the readers so they believe that they don't have to negotiate with the readers. That is the reason why monogloss is used more to describe the content of the reviewed book. 
For example:

(6) 全书有八章,由三部分组成:第一部分是概念部分(第一、二章),主要介绍相关的背景知识。第二部分是实证 部分(第三至第六章),也是全书的核心部分,主要讨论具体的语言现象。第三部分是总结部分(第七、八章),这部分 从更宽广的视角,详细呈现了该系统的整体结构。

(Translation: The book is composed of 8 chapters, 3 parts: the first part introduces the main concepts (chapter 1 and chapter 2), and it is mainly about the background knowledge. The second part is the empirical research (chapter 3 to chapter 6). This part is the main body of the whole book, and it talks mainly about linguistic phenomena. The third part is the conclusion (chapter 7 and 8). This part describes the structure of the system from a broader perspective.

Extra-vocalise is also found in the 30 Chinese academic book reviews. With the help of extra-vocalise, the book reviewer combine his/her voice with that of the book author, and thereby reduce the space for confliction.

(7) Hale和Keyser认为词汇与句法是可以相容的。

(Translation: Hale and Keyser believe that lexis and syntax are compatible.)

Sometimes, the book reviewer's voice and the book author's voice are mingled together, and it's difficult to discern the two. This is also a strategy book reviewers employ to make the review's opinion fuzzy, so as to reduce the potential risk of being challenged.

(8) 布斯希望全社会注重修辞教育的重要性.

(Translation: Buss hoped the whole society to pay attention to the significance of rhetorics education.)

Assimilation in example (8) makes it impossible to discern the reviewer's opinion from the book author-Buss' opinion.

\section{Appraisal at the Generic Stage of Evaluation}

The stage of Evaluation is the part where book reviewers feel free to express his/her subjective opinions. So the appraisal resources in this part outnumber the other two parts. With an understanding that they are expected by the readers to give an authoritative evaluation of the book and its author, the book reviewer employ more intra-vocalise to express his/her opinions. With intra-vocalise, contractive expressions outnumber that of the expansive expressions.

For example:

(9) 毫无疑问，西方修辞学史是一部深入探讨西方修辞的力作。

(Translation: There is no doubt that the history of Western rhetorics is a great work exploring deeply the rhetorics in the West.)

In most of the positive evaluations, contractive engagement expressions are employed by the book reviewers to express the reviewers' praises. While, for those negative comments, the book reviewers employ expansive engagement expressions so as to negotiate with different voices.

For example:

（10）我们相信，叙事重构在其日后问世的著作中会得到更深刻的讨论。

(Translation: We believe that the narrative reconstruction will be discussed more deeply in the author's future books.)

(11) 我认为, 对此部分的简略叙述也可能是作者有意为之。

(Translation: I think the author may deliberately give this part a brief description.)

In example (10), the expression "we believe" serves to expand the space for negotiation because the criticism is just "our" opinion. And in the statement following "we believe" is an expectation that the current problem will be solved in future research, which softens the criticism. In example (11). the expression "I think" is used for the same purpose-- to expand the following critical statement dialogically.

\section{CONCLUSION}

The present study aimed to employ appraisal theory to analyze Chinese academic book reviews. Its findings suggest that appraisal resources function effectively to help the book reviews to negotiate their inter-subjective positions with the book authors and the general readers. However, findings of the present study will be more complete if more studies are done about book reviews from other different academic fields. The research results would be more convincing if individual book reviewer is interviewed to talk about their understanding on writing book reviews, their relationship with the book authors, and their educational background regarding critical thinking.

\section{REFERENCES}

[1] Ana I. Moreno and Lorena Suarez. (2008). A study of critical attitude across English and Spanish academic book reviews. Journal of English for Academic Purposes (7):15-29.

[2] Hiroko Itakura and Amy B.M. Tsui. (2011). Evaluation in academic discourse: Managing criticism in Japanese and English book reviews. Journal of Pragmatics (43):1366-1379.

[3] Hyland, Ken. (2004). Disciplinary Discourses: Social Interactions in Academic Writing. University of Michigan Press, Ann Arbor, MI (First published by Pearson Education Limited, Longman, 2000).

[4] Lindholm-Romantschuk, Y. (1998). Scholarly book reviewing in the social sciences and humanities: The flow of ideas within and amongst disciplines. Westport, CT: Greenwood Press. 
[5] Martin, J. R. (1984). Language, register and genre. In Christie, F. (ed.), Language Studies Children Waiting. Reader (pp. 21-29). Geelong, Victoria: Deakin University Press.

[6] Martin, J. \& P. White. (2005). The Language of Evaluation: Appraisal in English. London and New York: Palgrave

[7] Voloshinov, V.N. (1995). Maxism and the Philosophy of Language, Bakhtinan Thought-an Introductory Reader. S. Dentith, L. Matejka \& I.R. Titunik,. London: Routledge.

[8] Salager-Meyer, Franc, oise, Alcaraz Arizas. (2004). Negative appraisals in academic book reviews: a cross-linguistic approach. In: Candlin, C., Gotti, M. (Eds.), Intercultural Aspects of Specialized Communication. Peter Lang, Bern, pp. 149-172.

Dongmei Wang was born in Changchun, Jilin, China in 1977. She received her MA degree in Applied Linguistics from Jilin University in 2002. She is currently a lecturer in the Department of Foreign Languages, Dalian University of Technology, Dalian, China. Her academic research mainly focuses on systemic functional linguistics and discourse analysis.

Xuehua An was born in Jilin, China, 1979. She got both her Bachelor's degree and Master's Degree in Dalian University of Technology. Her major is Foreign Language and Linguistics. From 2009 to 2010, she furthered education in National Institute of Education, in Nanyang Technological University, Singapore, from where her academic journey embarked. She is now a lecturer in School of Foreign Languages in Dalian University of Technology. Her research interests include teaching English as a second language, L2 writing and English for academic purpose. 